\title{
The relationship of genotype to cognitive outcome in galactosaemia
}

\author{
J P H Shield, E J K Wadsworth, A MacDonald, A Stephenson, L Tyfield, J B Holton, \\ N Marlow
}

\begin{abstract}
Aims-To evaluate the cognitive outcome of a cohort of children with galactosaemia in relation to genotype.

Methods-The cohort was drawn from children notified to the British Paediatric Surveillance Unit galactosaemia study which ran from 1988 to 1990 . Cognitive outcome was assessed using the Wechsler Intelligence Scale for Children or the Wechsler Preschool and Primary Scale of Intelligence. Parents completed a questionnaire detailing educational status, and the attending paediatrician returned a questionnaire regarding age at diagnosis and biochemical outcome over the previous two years.
\end{abstract}

Results-A total of 45 children were genotyped: 30 were homoallelic for the Q188R mutation, the remainder being heteroallelic for Q188R with K285N (n= 4), L195P $(n=4)$, or other mutations $(n=7)$. Psychometric evaluation was available in 34 cases: mean full scale IQ was 79 , verbal quotient 79 , and performance quotient 82 . Genotype was not related to galactose-1phosphate (Gal-1-P) concentrations. However, children homoallelic for the Q188R mutation had significantly lower IQ scores than those who were heteroallelic (73.6 $v$ 94.8). This difference was independent of social and demographic influences and Gal-1-P concentrations over the previous two years.

Conclusions-In children with galactosaemia, cognitive outcome appears to relate to genotype rather than metabolic control, as reflected by Gal-1-P concentrations. The value of measuring Gal-1-P concentrations routinely once successfully established on a galactosaemia diet is questionable as concentrations do not appear to affect outcome. In the UK population, homozygosity for the Q188R mutation is invariably associated with a poor outcome, and there is evidence that variability in neurocognitive outcome is at least part dependent on allelic heterogeneity.

(Arch Dis Child 2000;83:248-250)

Keywords: galactosaemia; genotype; cognitive and behavioural function; galactose-1-phosphate uridyl transferase

Prof N Marlow, Academic Division of Child Health, E Floor, East Block University Hospital, Queen's Medical Centre, Nottingham NG7 2UH, UK email: neil.marlow@ nottingham.ac.uk

Accepted 30 March 2000 of the enzyme galactose-1-phosphate uridyl transferase (GALT). ${ }^{1}$ Children with this condition normally present in the neonatal period with unconjugated hyperbilirubinaemia although overwhelming sepsis can also be a significant element at presentation. The initial illness resolves dramatically on the introduction of a galactose restricted diet but, despite good dietary restriction of galactose, children still have significant morbidity in later life.

An earlier study carried out in collaboration with the British Paediatric Surveillance Unit (BPSU) set out to ascertain and collect data on all cases of GALT deficiency within the United Kingdom and Republic of Ireland during a three year period from 1 January 1988 to 31 December 1990, with a view to examining whether neonatal screening might alter the natural history of clinical disease. ${ }^{2}$ This present study was designed to re-examine the progress of this cohort at or around the time of the seventh birthday, principally in relation to cognitive outcome and its relationship to genotype.

\section{Methods}

The clinicians identified from the original study were approached and asked to participate in the follow up study. Where care had been transferred to a colleague, this individual was then approached. The clinicians were asked to provide details of biochemical tests (either galactose-1-phosphate (Gal-1-P) or galactitol) performed over the previous two years, and to arrange a psychometric assessment (using the Wechsler Intelligence Scale for Children (WISC-III) or the Wechsler Preschool and Primary Scale of Intelligence (WPPSI)). Clinicians were also asked to provide blood for DNA extraction from the child to allow genotype analysis by the laboratories in either Bristol or Manchester. The parents were also approached with a questionnaire allowing assessment of parental educational status.

\section{STATISTICS}

Data were encoded for computer analysis using SPSS for Windows (version 7.5). Details of statistical tests are included in the results section. Multiple regression was carried out using the SPSS regression module.

\section{GENETIC ANALYSIS}

All samples were tested for the most common mutation, Q188R, using polymerase chain reaction (PCR) amplification of exon 6 and restriction enzyme digestion with either HpaII or $\mathrm{MspI}$. $^{3}$ The $\mathrm{A} \rightarrow \mathrm{G}$ transition at nucleotide c.563 creates a HpaII/MspI cutting site. A second cutting site at nt position c.443 acts as an internal control. Samples that were not homoallelic for the Q188R mutation were 
screened for mutations using denaturing gradient gel electrophoresis. Primer sequences for exons 2 to 11 were kindly provided by Professor Wolfgang Strobl. ${ }^{4}$ Any sample showing an altered banding pattern compared with control samples was sequenced. New mutations were sequenced in both directions to ensure that the base change was not an artefact of the PCR reaction.

\section{Results}

The median age of the children at the time of assessment was 6.4 years (range 4.0-8.6). Genotype has been assessed for 45 children: 30 are homoallelic for the Q188R mutation, and 15 heteroallelic (Q188R/K285N $(\mathrm{n}=4)$, Q188R/L195P ( $\mathrm{n}=4)$, Q188R/other $(\mathrm{n}=7$, with one further child having a near complete deletion of both copies of the galactosaemia gene, a condition encountered among Ashkanazey Jews).

GALACTOSE-1-PHOSPHATE CONCENTRATIONS

Half of the laboratories reporting Gal-1-P concentrations used $\mathrm{mmol} / \mathrm{l}$ red blood cells while the remainder used $\mu \mathrm{mol} / \mathrm{g} \mathrm{Hb}$. For this study, results given as $\mathrm{mmol} / \mathrm{l}$ red blood cells were converted to $\mu \mathrm{mol} / \mathrm{g} \mathrm{Hb}$ using the conversion factor 0.0032 , which is based on the assumption that the values for haemoglobin and haematocrit are both mean normal. The overall median Gal-1-P level over the two years prior to the assessment was $0.41 \mu \mathrm{mol} / \mathrm{g} \mathrm{Hb}$ $(r=0.16-0.88)$. Target concentrations for Gal$1-\mathrm{P}$ in clinical practice are set at $0.5 \mu \mathrm{mol} / \mathrm{gHb}{ }^{5}$

WISC-III AND WPPSI RESULTS

Scores were available for 34 children: mean IQ was $79(r=49-116)$. Furthermore, in 32 cases, mean performance score (PQ) was $79(r=49-$ 121) and mean verbal score (VQ) $82(r=52$ 121). For 10 children, scores were above 85 (1 standard deviation below the normative mean); in 21 , scores were $56-85$; and in three, scores lay below 56 .

IQ scores appear to be related to genotype. In 32 cases, both the genotype and psychometric assessment had been performed. The 23 children with the commonest UK genotype (homoallelic for Q188R) had lower scores compared to nine children with less common genotypes (mean full IQ scores: $74 v$ 95, $\mathrm{p}=0.01)$. Similar differences were observed in subscale scores (mean PQ: $73 v 95, \mathrm{p}=0.01$; mean VQ: $78 v 93, \mathrm{p}=0.05)$. Only three of nine heteroallelic cases scored less than 85 on full scale IQ compared to 18 of 22 homoallelic cases (Fisher exact $\mathrm{p}=0.015$ ). The child with an almost complete deletion of both genes was identified as having a full scale IQ of 60 .

A number of confounding factors that might be related to cognitive outcome were examined for association with IQ. Multiple regression analysis of demographic data revealed that mother's current age $(p=0.02)$ and educational level $(p=0.01)$ were related to IQ scores, while Gal-1-P concentrations and age at presentation were not. The association of IQ score with genotype remained significant when included in the model.

\section{Discussion}

Although the treatment for galactosaemia is theoretically simple and the median Gal-1-P level attained within this cohort indicates good adherence to dietary constraints, we are disappointed to note that the mean full scale IQ score within this group was well within the ranges described previously. ${ }^{67}$ Other authors have indicated that dietary control, as reflected in Gal-1-P concentrations, was a poor indicator of long term cognitive function, ${ }^{6}$ and we have further confirmed this observation. Although Gal-1-P remains the main indicator of dietary adherence, it has been recently suggested from observations in "knock out mice" that Gal-1-P might not be the only toxic metabolite involved in the pathogenesis of galactosaemic complications $^{8}$; recent guidelines for the management of galactosaemia emphasise the limitations of Gal-1-P measurements for determining and influencing outcome. ${ }^{5}$

In 1993, Elsas et al suggested that being homoallelic for the Q188R mutation conferred a poorer prognosis for eventual IQ than being heteroallelic, ${ }^{9}$ although this was refuted by two later studies. ${ }^{11} 11$ We now provide further evidence for a putative genotype/phenotype effect, as children homoallelic for Q188R invariably have poor IQ results. Certainly, individuals homoallelic for Q188R show undetectable erythrocyte GALT activity, and in vitro expression analysis has confirmed a substantial or complete loss of GALT activity. ${ }^{12}{ }^{13}$ The original postulation of Elsas et al requires further refinement given the large number of mutations now identified (approx. 150) in the GALT gene. Some mutations (splice site, frame shift deletions or insertions, and nonsense) in the homoallelic state or in association with a Q188R mutation would be expected to produce a severe biochemical phenotype and clinical outcome. ${ }^{14}$ In addition other mutations, namely K285N and L195P are associated with a complete loss of GALT activity and have been suggested to result in a more severe phenotype. ${ }^{1516}$ Interestingly, although too small in number for statistical evaluation, this study gives an impression that those with a Q188R/L195P and possibly the Q188R/K285N configuration also have a poor outcome in terms of IQ consistent with these observations.

Attempts to define influences on outcome for children with galactosaemia are hampered by the rarity of the disease process and therefore the geographical spread of cases. In addition the condition seems to be particularly common in travelling families, where the gene frequency may be high relative to the general UK population. Nonetheless the progressive cognitive, speech, and educational problems in children with this condition require prospective evaluation using validated and reliable measures to determine how they may be ameliorated, if at all. Our observation of the relationship with genotype has face validity, given the background laboratory work. The detailed determination of genotype may provide a way in which groups at risk for poorer outcome may be identified and studied. 
1 Dunger DD, Holton JB. Disorders of carbohydrate metabolism. In: Holton JB, ed. The inherited metabolic diseases, 2nd edition. Edinburgh: Churchill Livingstone, 1994:21-65.

2 Honeyman MM, Green A, Holton JB, Leonard JV. Galactosaemia: results of the British Paediatric Surveillance Unit study, 1988-1990. Arch Dis Child 1993;69:33941.

3 Elsas L, Langley S, Steele E, et al. Galactosemia: a strategy to identify new biochemical phenotypes and molecular genotypes. Am f Hum Genet 1995;56:630-9.

4 Greber-Platzer S, Guldberg P, Scheibenreiter S, Item C, Schuller N, Patel N, Strobl W. Molecular heterogeneity of classical and Duarte galactosemia mutation analysis by denaturing gradient gel electrophoresis. Hum Mutat 1997; 10:49-57.

5 Walter JH, Collins JE, Leonard JV, on behalf of UK Galactosaemia Steering Group. Recommendations for the management of galactosaemia. Arch Dis Child 1999;80:93-6.

6 Waggoner DD, Buist NRM, Donnelll GN. Long-term prognosis in galactosaemia: results of a survey of 350 cases. $f$ nosis in galactosaemia: results of

7 Schweitzer S, Shin Y, Jakobs C, Brodehl J. Long-term outcome in 134 patients with galactosaemia. Eur $\mathcal{f}$ Pediatr $1993 ; 152: 36-43$

8 Leslie ND, Yager CL, McNamara PD, Segal S. A mouse model of galactose-1-phosphate uridyl transferase deficiency. Biochem Mol Med 1996;59:7-12.

9 Elsas LJ, Fridovich-Keil JL, Leslie ND. Galactosaemia: a molecular approach to the enigma. International Pediatrics 1993;8:101-8.
10 Cleary MA, Heptinstall LE, Wraith JE, Walter JH. Galactosaemia: relationship of IQ to biochemical control and genotype. F Inherit Metab Dis 1995;18:151-2.

11 Kaufman FR, Reichardt JKV, Ng WG, Xu Y-K, Manis FR, McBride-Chang C, Wolff JA. Correlation of cognitive, neurologic, and ovarian outcome with the Q1888R mutation of the galactose-1-phosphate uridyltransferase gene. 7 Pediatr 1994;125:225-7.

12 Reichardt J, Packman S, Woo S. Molecular characterisation of two galactosaemia mutations: correlation of mutations with highly conserved domains in galactose-1-phosphate uridyl transferase. Am f Hum Genet 1991;49:860-7.

13 Geeganage S, Frey P. Transient kinetics of formation and reaction of the uridyl-enzyme form of galactose-1-P uridyltransferase and its Q168R-variant: insight into the molecular basis of galactosaemia. Biochemistry 1998;37:14500-7.

14 Tyfield L, Reichardt J, Fridovich-Keil J, et al. Classical galactosaemia and mutations at the galactose-1-phosphate uridyl transferase (GALT) gene. Hum Mutat 1999;13:41730.

15 Podskarbi T, Franzmann H, Kleinlein B, Gathof B, Shin Y. A genotype-phenotype correlation in classical galactosaemia. In: Demirkil M, Shin Y, ed. Diagnosis and treatment of inborn errors of metabolism. Istanbul: Turkish Society for PKU, 1996:56-9.

16 Sommer M, Gathof B, Podskarbi T, Guigliani R, Kleinlein B, Shin Y. Mutations in the galactose-1-phosphate uridyltransferase gene of two families with mild galactosaemia variants. F Inher Metab Dis 1995;18:567-76.

\section{A controversial expert witness}

No paediatrician relishes giving evidence to a court when it is alleged that a child's injuries were caused by his or her parent. The task is not made easier on those occasions when the defence argument seems to owe more to wishful thinking than demonstrable fact.

Five years ago, $A D C$ published a "Controversy" paper which discussed a particularly contentious defence argument, that of "temporary brittle bone disease", the existence of which was frequently championed in court by a particular expert witness. ${ }^{1}$

The argument continues: paediatricians who need to further their understanding of the legal position regarding this suggested entity would do well to read a paper published in the March 2000 issue of Family Law. ${ }^{2}$ They might wish to draw the attention of solicitors (attorneys), courts, and social service departments to the paper.

This is apposite to US readers as well as those in the UK because it details a US judge's forthright comments on evidence offered by the doctor in question as well as those already stated in a UK judgement. ${ }^{3}$

1 Smith R. Osteogenesis imperfecta, non-accidental injury and temporary brittle bone disease. Arch Dis Child 1995;72:16971 (commentaries: Wynne JM, Hobbs C. Ibid 171-2; Carty H. Ibid 174-6; Author's response. Ibid 174-6).

2 Williams C. A controversial expert witness. Family Law 2000;175-180.

3 Re AB (Child Abuse: Expert Witnesses) 1995; 1 FLR181. 